OPEN ACCESS

Edited by:

Raffaella Greco,

San Raffaele Hospital (IRCCS), Italy

Reviewed by:

Constanca Figueiredo,

Hannover Medical School, Germany

Thomas Luft,

Heidelberg University

Hospital, Germany

*Correspondence:

Federico Simonetta

federico.simonetta@unige.ch

Eddy Roosnek

eddy.roosnek@unige.ch

${ }^{\dagger}$ These authors have contributed equally to this work

Specialty section:

This article was submitted to Alloimmunity and Transplantation,

a section of the journal

Frontiers in Immunology

Received: 17 December 2019 Accepted: 27 April 2020 Published: 27 May 2020

Citation:

Pradier A, Masouridi-Levrat $S$,

Bosshard C, Dantin C, Vu D-L, Zanella M-C, Boely E, Tapparel C, Kaiser L, Chalandon Y, Simonetta F and Roosnek E (2020) Torque Teno Virus as a Potential Biomarker for

Complications and Survival After Allogeneic Hematopoietic Stem Cell Transplantation.

Front. Immunol. 11:998.

doi: 10.3389/fimmu.2020.00998

\section{Torque Teno Virus as a Potential Biomarker for Complications and Survival After Allogeneic Hematopoietic Stem Cell Transplantation}

\author{
Amandine Pradier ${ }^{1}$, Stavroula Masouridi-Levrat ${ }^{1}$, Carine Bosshard ${ }^{1}$, Carole Dantin ${ }^{1}$, \\ Diem-Lan Vu ${ }^{2}$, Marie-Céline Zanella ${ }^{2}$, Elsa Boely ${ }^{2}$, Caroline Tapparel ${ }^{2}$, Laurent Kaiser ${ }^{2}$, \\ Yves Chalandon ${ }^{1}$, Federico Simonetta ${ }^{1,3 * t}$ and Eddy Roosnek ${ }^{1 * t}$ \\ ${ }^{1}$ Division of Hematology, Department of Oncology, Faculty of Medicine, Geneva University Hospitals, Geneva, Switzerland, \\ ${ }^{2}$ Division of Infectious Diseases, Department of Medicine, Faculty of Medicine, Geneva University Hospitals, Geneva, \\ Switzerland, ${ }^{3}$ Translational Research Center for Oncohematology, Department of Internal Medicine Specialties, University of \\ Geneva, Geneva, Switzerland
}

Impaired immune reconstitution after allogeneic hematopoietic stem cell transplantation (HSCT) contributes to increased risk of cancer relapse and infection resulting in significant morbidity and mortality. Unfortunately, effective strategies to functionally assess the quality of immune reconstitution are still missing. Quantification of in vivo replication of the ubiquitous, non-pathogenic virus Torque Teno Virus (TTV) has been reported in small series as a test to functionally evaluate the quality of post-transplant immune reconstitution. In the present study, we analyzed by quantitative PCR TTV titers in plasma samples from a large cohort of 168 allogeneic HSCT recipients. Our analysis confirms that TTV titers peaked at 100 days post-transplant, followed by progressive normalization thereafter. Negative correlation of TTV titers with T cell absolute numbers during the first year post-transplant points to the restoration of an active anti-TTV immunity. Univariable and multivariable linear regression analysis demonstrated that donor CMV positive serostatus, donor type and immune suppression resulting from GVHD treatment affected the restoration of anti-TTV immunity. Importantly, higher TTV titers at 100 days after transplantation were associated with worse overall survival and higher risk of acute GVHD and infections. Our results provide new insights into the factors affecting the dynamics of TTV replication and indicate that TTV is a potentially useful biomarker to assess immune reconstitution and to predict complications and outcomes of allogeneic HSCT.

Keywords: TTV, biomarker, CD4, GVHD, HSCT, immunocompetence

\section{INTRODUCTION}

Hematopoietic stem cell transplantation (HSCT) is an established treatment for a broad range of hematological disorders. Unfortunately, the pre-transplant conditioning regimen and post-HSCT immunosuppressive therapies induce quantitative and qualitative abnormalities in HSCT recipients' immune system that can result in a severe and often long-lasting immunodeficient 
status. Impaired immune reconstitution significantly increases the risk of both relapse and transplant related mortality (1-7). Efficient strategies to monitor immune reconstitution are therefore critically important to guide prophylactic and therapeutic interventions. Immunocompetence is difficult to quantify and immune monitoring strategies after allogeneic HSCT vary widely from one center to another (8). The number of T cells is often used as a marker for immune reconstitution (8) but this may be inaccurate because T cells may normalize without restoring immunity (9).

Measuring immunity against ubiquitous, non-pathogenic viruses may represent a test to functionally evaluate posttransplant immune reconstitution. Torque teno virus (TTV), a small non-enveloped anellovirus with a circular single stranded DNA of about $3.8 \mathrm{~kb}$, is highly prevalent in the general population (10) and considered to date to be non-pathogenic with no known associated specific clinical manifestations (11). Plasma levels in immunocompetent individuals are low (12), but HIV infection $(13,14)$, immune suppression (15-19) or cancer treatment (20) allow the virus to escape immune surveillance and replicate. Importantly, replication of TTV is not affected by antiviral therapies (21). For these reasons several studies assessed the quantification of TTV titers as a precise and straightforward method to measure the patient's immunity. TTV levels after solid organ transplantation (16-19, 21-27) or HSCT (28-34) correlate with the intensity of immunosuppressive treatment and are associated with complications such as rejection $(19,21,23-25,35,36)$, infections $(18,25-27,33,35)$ or GVHD (30-32, 37).

In this study we prospectively investigated the kinetics of TTV titers and assessed their relationship with clinical parameters and post-transplant reconstitution in a large cohort of allogeneic HSCT recipients. Moreover, we assessed the potential association of TTV titers at day 100 after HSCT with clinical outcomes and post-HSCT complications.

\section{METHODS}

\section{Study Protocol and Patients' Data}

One hundred and thirty three adult ( $\geq 18$ years) patients undergoing a first HSCT for hematological malignancies were enrolled in the study between 2012 and 2015 [91 patients were included in our previous study evaluating TTV titers at time of transplantation (30)]. 3 patients were excluded for early graft failure. In addition, 38 patients transplanted 2 to 9 years before enrolment were recruited. Peripheral blood samples were collected at day $0,50,100,150,200,300,400$, 547 and 2 to 9 years post-HSCT (Supplementary Table 1). Patients' characteristics and transplantation related data are presented in Table 1. Ninety one healthy donors [74 of them already included in our previous study (30)] from the Geneva University Hospitals blood transfusion center were also analyzed as a control group. The study was approved by the local ethical committee $\left(\mathrm{n}^{\circ} 12-138\right)$ and patients and healthy controls (HC) gave their written informed consent.
TABLE 1 | Clinical characteristics of HSCT patients.

\begin{tabular}{|c|c|c|c|}
\hline \multicolumn{2}{|c|}{ Patients and transplant characteristics } & \multicolumn{2}{|c|}{ Patients $(n=168)$} \\
\hline Age, median (IQR) & & 51 & $(39-59)$ \\
\hline \multirow[t]{2}{*}{ Sex, $n(\%)$} & $\mathrm{F}$ & 64 & (38) \\
\hline & $\mathrm{M}$ & 104 & $(62)$ \\
\hline \multirow[t]{7}{*}{ Diagnosis, $n(\%)$} & AML & 78 & $(46)$ \\
\hline & ALL & 17 & $(10)$ \\
\hline & MDS & 22 & $(13)$ \\
\hline & MPS & 11 & $(7)$ \\
\hline & Lymphoma & 12 & (7) \\
\hline & Myeloma & 11 & $(7)$ \\
\hline & others & 17 & $(10)$ \\
\hline \multirow[t]{2}{*}{ Status at HSCT, $n(\%)$} & CR & 108 & (64) \\
\hline & No CR & 60 & (36) \\
\hline \multirow[t]{2}{*}{$\mathrm{DRI}, n(\%)$} & High/very high & 56 & (33) \\
\hline & Low/intermediate & 112 & $(67)$ \\
\hline \multirow[t]{2}{*}{ Graft, $n(\%)$} & PBSC & 149 & (89) \\
\hline & $\mathrm{BM}$ & 19 & $(11)$ \\
\hline \multirow[t]{2}{*}{ Conditioning, n (\%) } & $\mathrm{RIC}$ & 85 & $(51)$ \\
\hline & MAC & 83 & $(49)$ \\
\hline \multirow[t]{4}{*}{ Donor type, $n$ (\%) } & SIB & 71 & $(42)$ \\
\hline & MUD & 75 & $(45)$ \\
\hline & MMUD & 13 & (8) \\
\hline & Haplo & 9 & (5) \\
\hline \multirow[t]{5}{*}{ T depletion, $n(\%)$} & None & 30 & (18) \\
\hline & ATG & 60 & (36) \\
\hline & pTCD & 19 & (11) \\
\hline & ATG+pTCD & 50 & $(30)$ \\
\hline & PTCy & 9 & $(5)$ \\
\hline \multirow[t]{4}{*}{ CMV status, $n(\%)$} & D-/R- & 47 & (28) \\
\hline & D-/R+ & 18 & $(11)$ \\
\hline & $\mathrm{D}+/ \mathrm{R}-$ & 28 & (17) \\
\hline & $\mathrm{D}+/ \mathrm{R}+$ & 75 & $(45)$ \\
\hline
\end{tabular}

CR, complete remission; DRI, Disease Risk Index; PBSC, peripheral blood stem cell; $B M$, bone marrow; RIC, reduced-intensity conditioning; MAC, myeloablative conditioning; $S I B$, identical sibling; MUD, matched unrelated donor; MMUD, mismatched unrelated donor; ATG, anti-thymocyte globulin; PTCD, partial T cell depletion; PTCy, posttransplant Cyclophosphamide.

\section{Clinical Protocols}

Myeloablative conditioning (MAC) usually consisted of cyclophosphamide (CY $120 \mathrm{mg} / \mathrm{kg}$ ) in combination with total body irradiation (10-12 Gy) or busulfan (12.8 $\mathrm{mg} / \mathrm{kg}$ intravenously). Reduced intensity conditioning (RIC) mainly consisted of fludarabine $\left(150 \mathrm{mg} / \mathrm{m}^{2}\right)$ associated with low dose busulfan (6.4 mg/kg intravenously) or melphalan (140 $\mathrm{mg} / \mathrm{m}^{2}$ ). T cell depletion (TCD) consisted of administration of anti-thymocyte globulin (ATG) and/or "in vitro" partial T cell depletion (pTCD) of grafts. ATG (ATG-Thymoglobulin ${ }^{\circledR} 7.5$ $\mathrm{mg} / \mathrm{kg}$ or ATG-Fresenius ${ }^{\circledR} 25 \mathrm{mg} / \mathrm{kg}$ ) was part of conditioning for all patients treated with RIC and for patients receiving grafts from an unrelated donor after a MAC. pTCD grafts obtained through in vitro incubation with alemtuzumab (Campath ${ }^{\circledR}$ [Genzyme Corporation, Cambridge, MA]), were washed before 
infusion and administered at day 0 , followed on day +1 by an add-back of unmanipulated grafts containing about $100 \times$ $10^{6} / \mathrm{kg}$ donor T cells (38). Graft-vs.-host disease prophylaxis mainly consisted of cyclosporine (for 3 months duration in the absence of GVHD in the case of pTCD and for 6 months for T-cell replete graft recipients) in combination with either methotrexate (MTX), in case of MAC, or mycophenolate mofetil (MMF) for patients transplanted after RIC. pTCD graft recipients also received methylprednisolone on days -2 and -1 . Patients receiving grafts from haploidentical donors received CY $(50 \mathrm{mg} / \mathrm{kg})$ on days 3 and 4 post-HSCT (PTCy). Donor lymphocyte infusions (DLI) at incremental doses starting with $1 \times 10^{6} \mathrm{CD} 3 / \mathrm{kg}$ were given at 3 months to all patients who had received pTCD grafts with RIC in the absence of GVHD or independently of TCD to patients with decreasing donor chimerism or in relapse. Acute or chronic GVHD was treated with corticosteroids alone or in combination with mycophenolate mofetil and/or cyclosporine.

\section{Detection of TTV Viral DNA}

Isolation of DNA from frozen plasma was performed using the Nuclisens ${ }^{\circledR}$ Easymag ${ }^{\circledR}$ system (BioMérieux) according to manufacturer's instructions. Plasma were spiked with Canine Distemper Virus (CDV) to control for DNA extraction and serial dilutions of TTV-containing plasmid standard were used for quantification (39). Taqman-based quantitative PCR with primers described by Moen et al. (12) for TTV and Tapparel et al. (40) for CDV was performed. Limit of detection was 25 copies $/ \mathrm{ml}$ of plasma and the linear amplification ranged from 250 to $2.5 \times 10^{9}$ copies $/ \mathrm{ml}$. Patients were considered to control TTV adequately when they had reduced TTV titers below the 90th percentile of the HC group (4 log copies/ml) thereafter.

\section{Flow Cytometry}

Fresh peripheral blood samples underwent red blood cell lysis and cells were stained with monoclonal antibodies specific for the following antigens: CD4 (FITC, clone OKT4, Biolegend), CCR7 (PE, clone 150503, R\&D Systems), CD3 (PerCPCy5.5, clone UCHT1, Biolegend), CD8 (APC, clone SK1, Biolegend), CD45 (Alexa Fluor 700, clone HI30, Biolegend), CD56 (Brilliant Violet 421, clone HCD56, Biolegend), CD45RA (Brilliant Violet 510, clone HI100, Biolegend). Data acquired on a Navios flow cytometer (Beckman Coulter) were analyzed with FlowJo ${ }^{\mathrm{TM}}$ software (FlowJo LLC). Subsets of CD4 and CD8 where defined according to CD45RA and CCR7 expression as follows: Naïve $\mathrm{T}$ cells $\left(\mathrm{T}_{\mathrm{N}}\right)$ CD45RA+/CCR7+, central memory $\mathrm{T}$ cells $\left(\mathrm{T}_{\mathrm{CM}}\right)$ CD45RA-/CCR7+, effector memory $\mathrm{T}$ cells ( $\mathrm{T}_{\mathrm{EM}}$ ) CD45RA/CCR7- and effector memory re-expressing CD45RA T cells (TEMRA) CD45RA+/CCR7-.

\section{Statistical Analysis}

Continuous variables were expressed as median with interquartile range and compared using the non-parametric Mann-Whitney test. Spearman's test was used to determine correlations. Kaplan-Meier's estimates were employed to determine the probability of 2 year overall survival (OS), and progression-free survival (PFS) and differences were determined using the Log-rank Mantel-Cox test. Cox regression was used to examine the independent impact of clinical factors (disease type, disease status, DRI, ATG, pTCD, donor type, and donor CMV serostatus) on OS and PFS. Cumulative incidence estimates of relapse, acute GVHD (grade 2-4) and infections were compared using the Gray test for univariable analysis and the Fine-Gray method for proportional hazard regressions (variables: ATG, pTCD, donor CMV serostatus, disease status, disease type, donor type, and DRI for relapse). Death without relapse and GVHD requiring systemic treatment were considered competing events for relapse. Death and relapse were used as competing events for GVHD. Death, relapse and GVHD requiring systemic treatment were considered competing events for infections. Statistical analysis was performed using Prism version 7 (GraphPad Inc.), $R$ version 3.5.1 [Comprehensive $R$ Archive Network (CRAN) project (http://cran.us.r-project.org)] with $\mathrm{R}$ studio Version 1.1.453. $P<0.05$ were considered significant.

\section{RESULTS}

\section{TTV Kinetics and Correlation With Immune Reconstitution During the First 2 Years Post-HSCT}

We first measured TTV titers in a cohort of 168 patients at transplant as well as at regular time points thereafter (Figure 1A and Supplementary Table 1). Patients' characteristics and transplantation related data are presented in Table 1. TTV titers in plasma of $91 \mathrm{HC}$ were used as reference (median TTV $2.2 \mathrm{log}$ copies/ml, IQR 0-3.1; Figure 1A). TTV titers post-HSCT varied from undetectable to $10 \log$ copies $/ \mathrm{ml}$ of plasma. At transplant, the median TTV titer was $2.4 \log$ copies/ml (IQR 0-3.7). TTV titers that had increased slowly over the first 30 days post-HSCT augmented rapidly thereafter to reach a peak at day 100 (median $6.4 \log$ copies/ml, IQR 5.1-7.7). At day 100, only $13 \%$ of patients were able to control TTV viremia $(<4 \log$ copies $/ \mathrm{ml})$ while at the end of the first year (day 400), $44 \%$ of patients had restored sufficient immunity to control TTV viremia. 27/34 (79\%) of patients that could be tested after 4 years post-transplant showed TTV levels below 4 log copies/ml (Figure 1A). We next measured the reconstitution of lymphocyte subsets in the same blood samples drawn to determine TTV titers (Figure 1B). NK cells were the first lymphocytes to recover with only $16 \%$ of patient having NK cell counts below the lower normal limit at day 50 (lower normal limit $=50 \mathrm{NK} / \mu \mathrm{l}$; median $155 \mathrm{NK}$ cells $/ \mu \mathrm{l}$, IQR 82-320), while T cells reconstituted more slowly. By day $400,16 \%$ of patients had CD4 T cells above the lower normal limit of $410 \mathrm{CD} 4 / \mu \mathrm{l}$ (median $192 \mathrm{CD} 4 / \mu \mathrm{l}$, IQR 81-332) and $76 \%$ of patients had CD8 $\mathrm{T}$ cells above lower normal limit (lower normal limit $=190 \mathrm{CD} 8 / \mu \mathrm{l} ; 362 \mathrm{CD} 8 / \mu \mathrm{l}$, IQR 194-1,045). To investigate the relationship between TTV titers and immune reconstitution we performed a correlation analysis between the number of lymphocyte in each subset and TTV titers (Figure 1C and Supplementary Table 2). At day 100, TTV levels inversely correlated with the number of lymphocytes and more specifically with the number of $\mathrm{CD} 4 \mathrm{~T}$ cells and NK cells. Correlation between TTV and CD4 could be observed until day 300 and, 
A
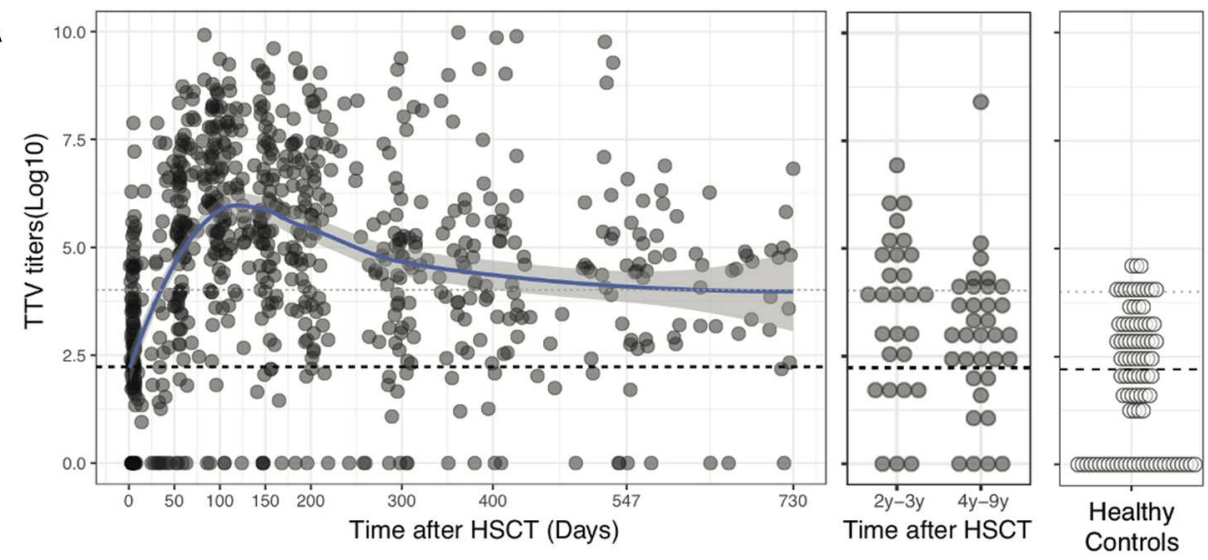

B

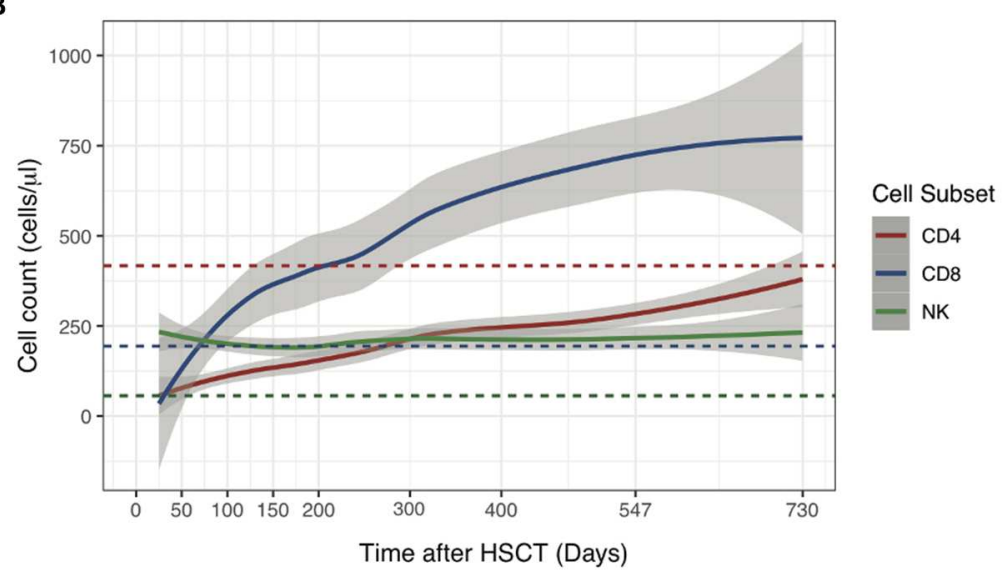

C

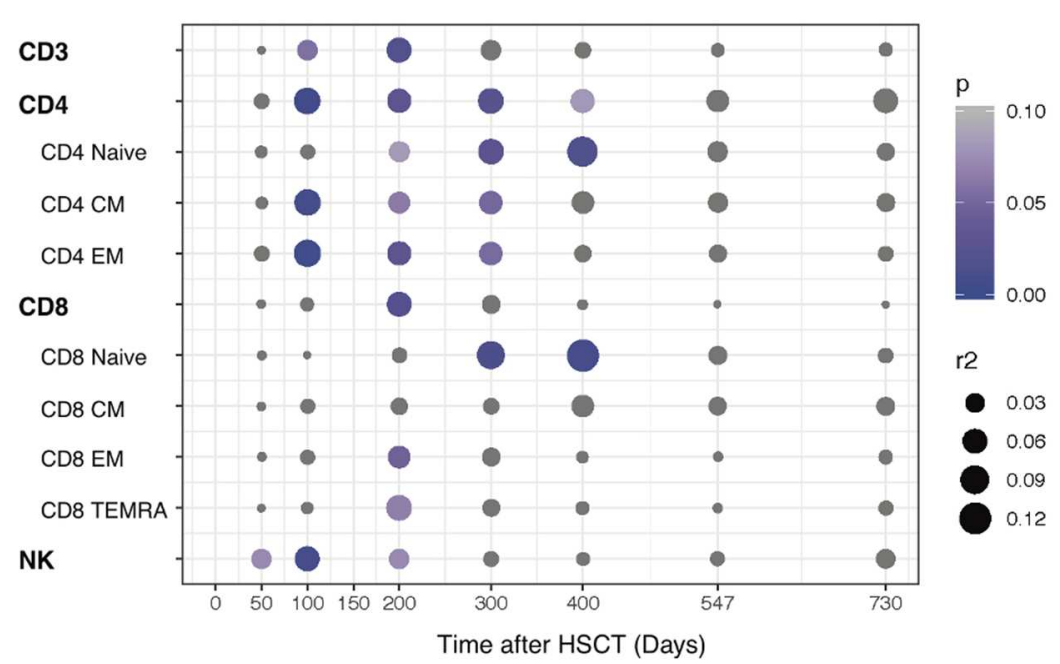

FIGURE 1 | TTV kinetics and correlation with immune reconstitution post-HSCT. (A) Data show TTV titers in Log copies/ml of plasma detected in 168 patients up to 9 years post-HSCT or in 91 Healthy Controls $(\mathrm{HC})$. Gray dots represent each sample, blue line represents Loess fit line and the gray area represents the $95 \%$ confidence interval (Cl) for the regression fit. Median (black dashed line) and 90th percentile (gray dotted lines) of TTV in HC are represented. (B) Loess fit lines for the number of NK, CD4, and CD8 in cells/ $\mu$ l are shown post-HSCT. Gray areas represent the $95 \% \mathrm{Cl}$ for the regression fit. (C) Correlation between log TTV titer and number of immune cells subsets post-HSCT are presented. The heat map shows Spearman's correlation coefficient and summary of $p$-values for each correlation post-HSCT. 

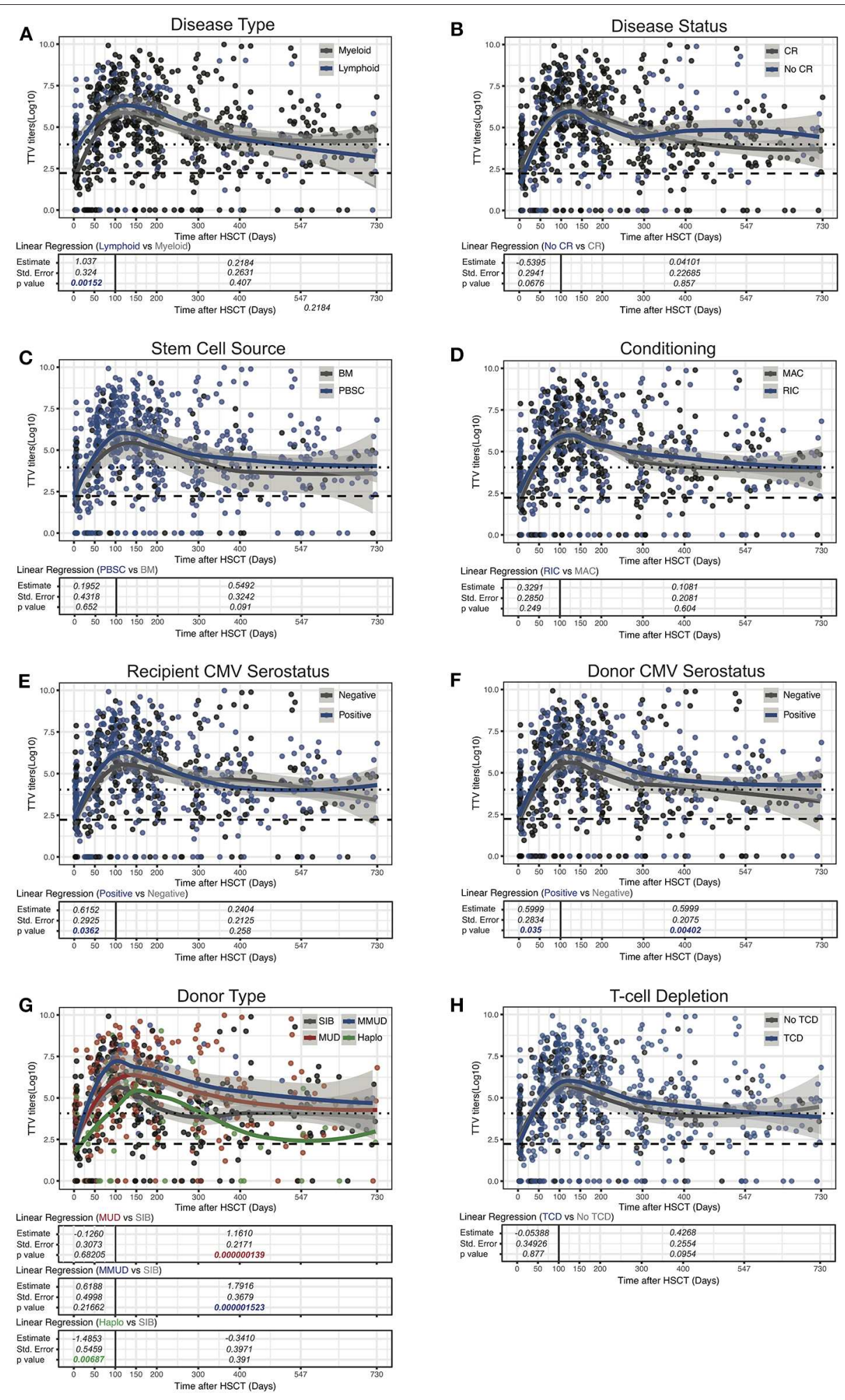

FIGURE 2 | Influence of clinical parameters on TTV titer kinetics in HSCT patients. Data show TTV titers in Log copies/ml of plasma depending on disease Type (A), disease status (B), stem cell source (C), conditioning (D), recipient/donor CMV status (E,F), donor type (G), and T-cell depletion (H) are shown. Dots represent each sample, lines represent Loess fit lines for each group and the gray area represents the $95 \% \mathrm{Cl}$ for the regression fit. Estimate, standard error and $p$-values resulting from univariable linear regression analysis are indicated from day 0 to 100 and day 100 to 730 . Median (black dashed line) and 90th percentile (gray dotted lines) of TTV in $\mathrm{HC}$ are represented. 


\begin{tabular}{|c|c|c|c|c|c|c|c|}
\hline \multirow[b]{2}{*}{ Variable } & & \multicolumn{6}{|c|}{ Time after HSCT } \\
\hline & & Estimate & Std.error & $p$-value & Estimate & Std.error & $p$-value \\
\hline \multicolumn{8}{|c|}{ Disease Type } \\
\hline & Lymphoid vs. Myeloid & 1.16558 & 0.30327 & 0.00015 & 0.50480 & 0.26059 & 0.05334 \\
\hline \multicolumn{8}{|c|}{ Stem Cell Source } \\
\hline & PBSC vs. BM & -0.16618 & 0.47058 & 0.72422 & 0.48762 & 0.38754 & 0.20894 \\
\hline \multicolumn{8}{|c|}{ Conditioning } \\
\hline & RIC vs. MAC & 0.17429 & 0.30546 & 0.56871 & 0.30143 & 0.24695 & 0.22286 \\
\hline \multicolumn{8}{|c|}{ CMV Serostatus } \\
\hline & MMUD vs. SIB & 0.11550 & 0.52532 & 0.82613 & 1.89318 & 0.44265 & 0.00002 \\
\hline & Haploidentical vs. SIB & -2.63122 & 0.80736 & 0.00124 & -0.02353 & 0.73214 & 0.97437 \\
\hline \multicolumn{8}{|c|}{ T-cell Depletion } \\
\hline & ATG & 0.09700 & 0.40319 & 0.81004 & -0.36422 & 0.33804 & 0.28185 \\
\hline & pTCD & -0.15317 & 0.58536 & 0.79376 & 0.61423 & 0.43423 & 0.15789 \\
\hline & ATG pTCD & 0.39477 & 0.44782 & 0.37871 & 0.39199 & 0.33908 & 0.24827 \\
\hline & РTCy & 0.66309 & 0.96078 & 0.49062 & -0.32707 & 0.84003 & 0.69719 \\
\hline \multicolumn{8}{|c|}{ GVHD before sampling } \\
\hline & Previous GVHD vs. No GVHD & 2.59324 & 0.32105 & $<0.00001$ & 0.51264 & 0.22753 & 0.02472 \\
\hline
\end{tabular}

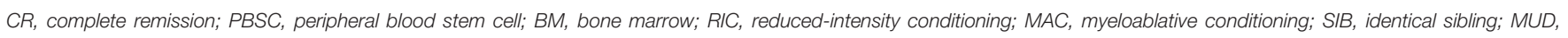

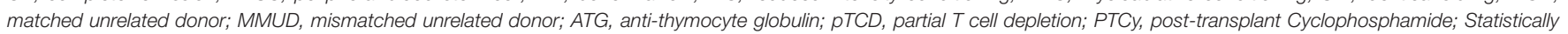
significant results are highlighted in bold.

from day 300 to 400, TTV titers mainly inversely correlated with CD4 and CD8 naïve subsets characteristic of a thymic rebound (41). No significant correlation with any cell subset was observed before day 100 and after day 400. TTV is known to replicate in hematopoietic cells (29) and TTV titers might therefore also reflect hematopoietic reconstitution in addition to immune-reconstitution. To assess the potential contribution of the hematopoietic reconstitution on TTV titers after transplant, we similarly performed a correlation analysis between total white blood cell (WBC) counts and TTV titers at different time points. We observed an inverse correlation between TTV levels and WBC at day 100 while no correlation was observed at other time points (Supplementary Figure 1).

Collectively, our results confirmed in a large cohort of patients the previously reported kinetics of TTV replication after allogeneic HSCT and uncovered an inverse correlation between TTV titers and immune cell numbers during the first year post-transplant.

\section{Transplant Characteristics Significantly Affect TTV Titers After Allogeneic HSCT}

We next assessed the impact of clinical factors on TTV titers over the first 2 years after transplantation performing linear regression analysis. Given the biphasic shape of the TTV titers curve post-HSCT (Figure 1A), we separately analyzed time periods before and after day 100. As we and others previously reported $(30,42)$, patients transplanted for lymphoid malignancies had significantly higher TTV levels at transplant (median 4 log copies/ml, IQR 2.5-5.2) than patients with myeloid malignancies (2.2 log copies/ml, IQR 0-3.2; $p<0.0001$ ). This baseline difference significantly impacted TTV kinetics during the first 100 days, but had little impact thereafter (Figure 2A). This difference could also be observed in the multivariable analysis $(p=0.0001$; Table 2). Factors such as disease status, stem cell source or conditioning had no effect on post-transplant TTV viremia (Figures 2B-D). Recipient and donor positive CMV serostatus was also associated with higher TTV levels in univariable analysis (Figures 2E,F) while multivariable analysis confirmed an association only with CMV positive donor ( $p$ $=0.0211$; Table 2). The strongest association was observed with donor type showing higher TTV viremia for MUD ( $p$ $<0.0001)$ and MMUD $(p<0.0001)$ when compared to SIB donors (Figure 2G). Such a difference was confirmed by the multivariable analysis $(p<0.0001$; Table 2). Patients receiving grafts from haploidentical donors followed by PTCy showed a delay in TTV titers increase early post-HSCT compared to 


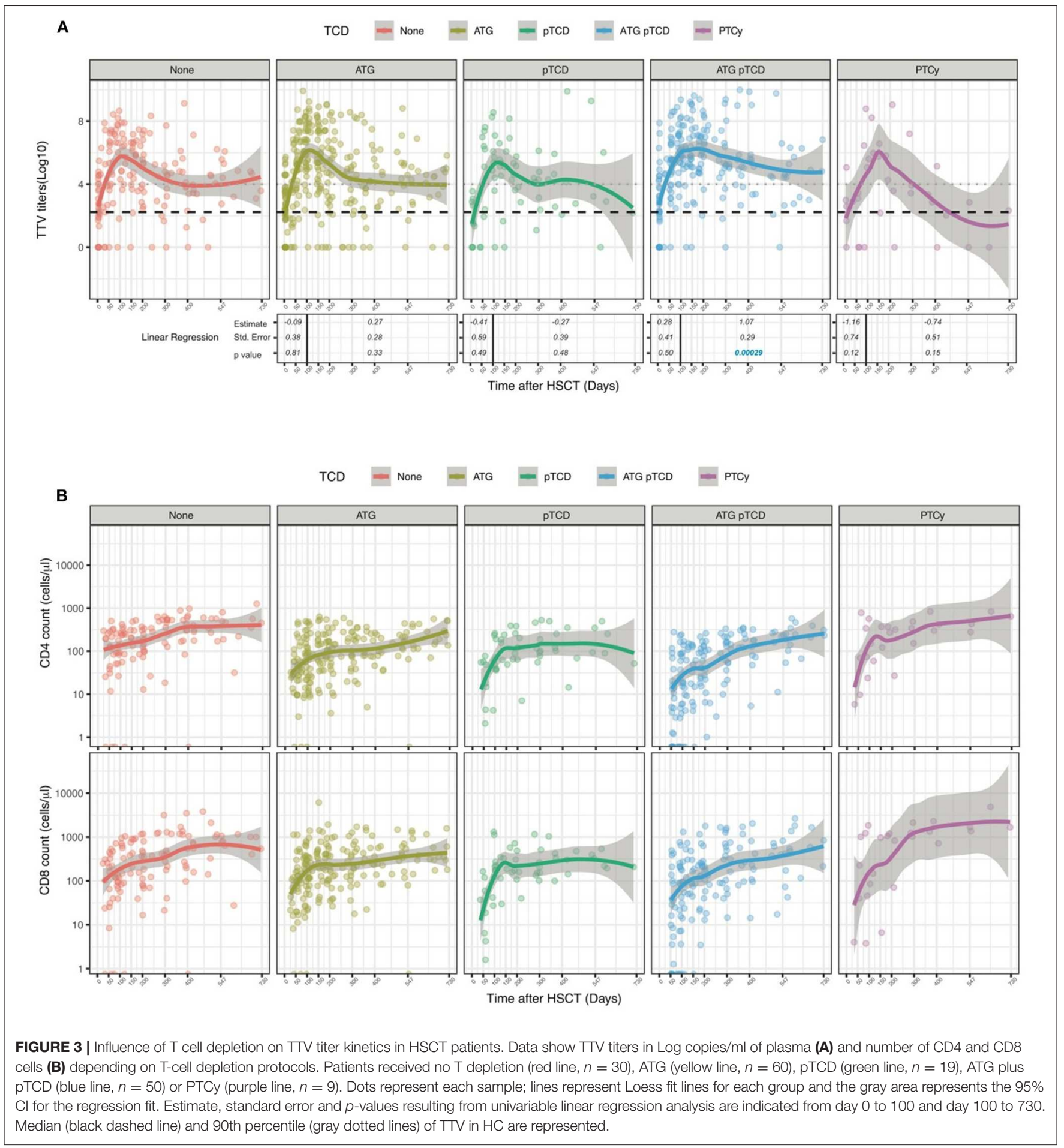

SIB donors ( $p=0.00687$; Figure 2G and Table 2). In these 9 patients, TTV levels remained low over the first 50 days (median $2.9 \log$ copies/ml, IQR 0-3.5 for PTCy vs. $5.7 \mathrm{log}$ copies $/ \mathrm{ml}$, IQR 4-7.2 for no TCD; $p=0.0004)$ but rose sharply thereafter reaching their peak at day 150 (5.8 log copies/ml, IQR 4.7-6.6). However, restoration of anti-TTV immunity thereafter was not impaired. We next compared TTV titers in patients in whom
$\mathrm{T}$ cells were depleted (TCD) by in vivo administration of antithymocyte globulin (ATG) and/or by partial $\mathrm{T}$ cell depletion (pTCD) of the graft and in patients with no TCD. Overall, TTV kinetics in patients receiving TCD were similar to those in no TCD group (Figure 2H). Upon examination of the different TCD methods, only patients receiving ATG together with pTCD grafts exhibited TTV titers higher than no TCD patients $(p=0.00029$; 
Figure 3A) although the multivariable analysis failed to confirm these differences (Table 2). The absence of significant difference in TTV kinetics in patients receiving TCD contrasted with the overall delayed $\mathrm{T}$ cell reconstitution observed in these patients (Figure 3B and Supplementary Table 3).

Collectively, these results demonstrated an impact of disease type and donor characteristics on TTV kinetics after allogeneic HSCT.

\section{GVHD and Its Treatment Significantly Impact TTV Titers}

To examine the effect of GVHD and its treatment on anti-TTV immunity, we stratified the patients based on the development of acute or chronic GVHD requiring systemic immune-suppression in the first 2 years post-HSCT. 83 patients suffered from GVHD requiring systemic treatment which occurred at a median day 50 (IQR 20-137). Patients received corticosteroids (82 patients), calcineurin inhibitors (75 patients), MMF (31 patients), photopheresis (16 patients), or basiliximab (4 patients). Univariable linear regression analysis demonstrated that after the onset of GVHD, patients had significantly higher TTV levels than patients without GVHD (d0-100: $p<0.00001$ and $\mathrm{d} 100$ 730: $p<0.001$; Figure 4A). TTV titers were significantly higher at day 100 in patients affected by GVHD (median 6.9 log copies/ml, IQR 5.4-7.9) compared with patients not experiencing the complication (5.6 log copies/ml, IQR 4.4-6.6; $p=0.013$ ). This association was confirmed in the multivariable analysis (Table 2). It is notable that during the first year post-HSCT the number of CD4 and CD8 T-cells in patients with GVHD remained significantly lower than in patients without GVHD (Figure 4B and Supplementary Table 4).

Twenty-three patients relapsed over the study period and no differences in TTV titers could be observed between these patients and patients who did not relapse (Supplementary Figure 2). However, due to the great heterogeneity in underlying diseases and relapse treatments it is difficult to draw any solid conclusions.

These data indicate that post-transplant complications, namely GVHD, and immunosuppressive drugs employed for its treatment have an impact on TTV replication kinetics.

\section{Higher TTV Titers at Day 100 Are Associated With Worse Overall Survival and Increased Risk of GVHD and Infections}

We next performed a landmark analysis to assess the potential association between TTV titers measured at day 100 and outcome after allogeneic HSCT. The landmark analysis was restricted to 58 patients that were alive without evidence of disease relapse and/or GVHD requiring systemic treatment at day 100. Patients displaying day 100 TTV titers in the upper quartile (threshold of $6.705 \mathrm{log}$ copies/ml) displayed a significantly worse 2 year OS $(50 \%$, 95\%CI $30-84 \%)$ compared to patients with lower TTV titers (82, 95\% CI 71-94\%; Figure 5A). Such a difference was confirmed in a multivariable analysis performed taking into account transplant and disease characteristics (HR 3.5, 95\% CI 1.1-11; $p=0.03$; Figure 5B). Univariable analysis similarly

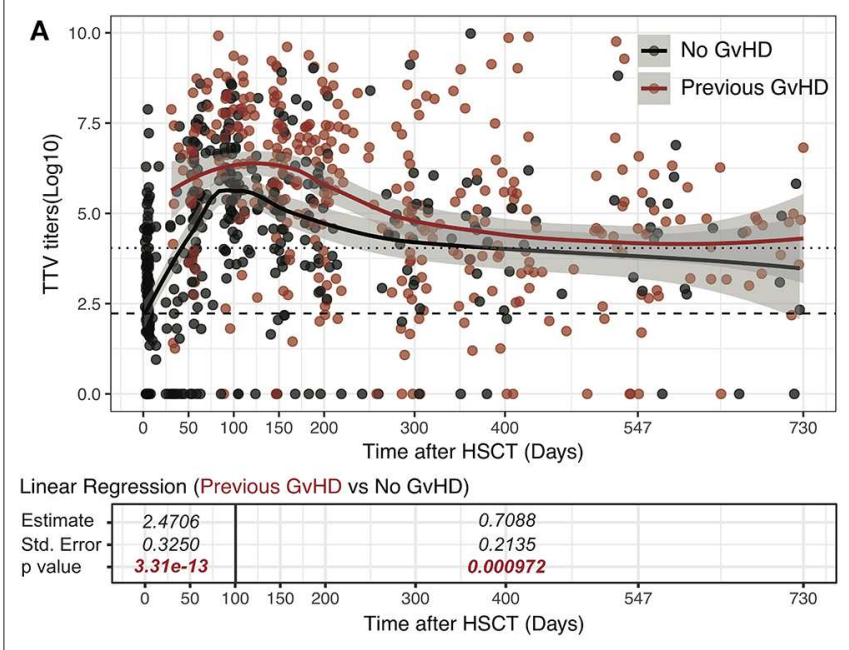

B

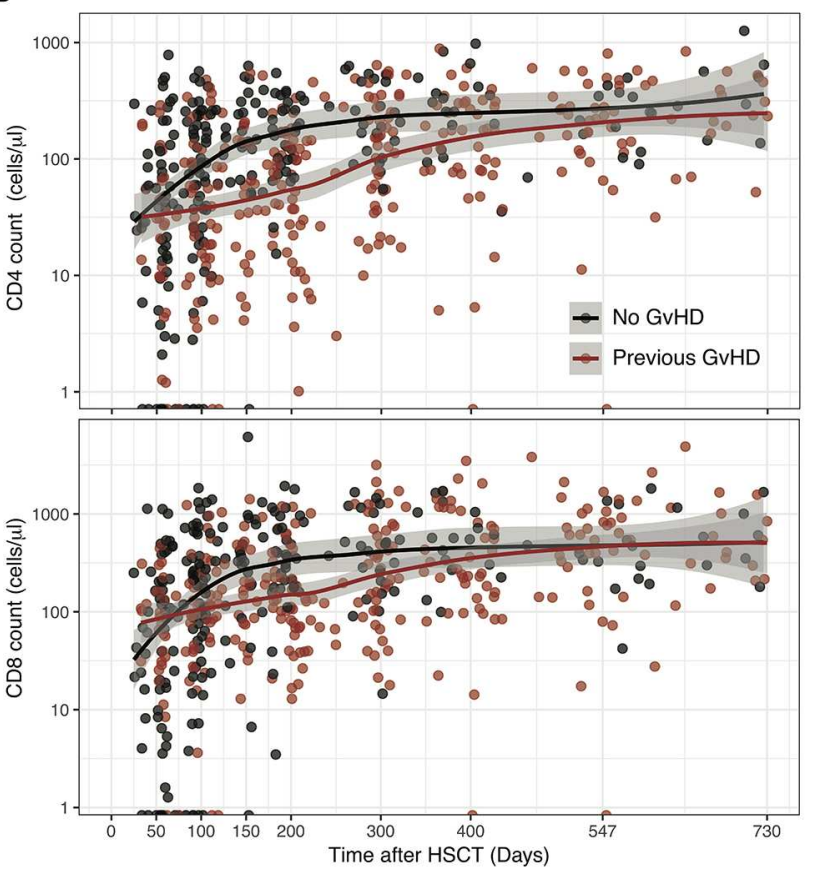

FIGURE 4 | Influence of GVHD occurrence on TTV titer kinetics in HSCT patients. Log TTV copies/ml of plasma (A) and number of CD4 and CD8 cells (B) are represented. Patients' samples obtained after onset of GVHD requiring immunosuppression are depicted in red and compared to samples obtained from patients without GVHD (black dots). Lines represent Loess fit lines for each group and the gray area represents the $95 \% \mathrm{Cl}$ for the regression fit. Estimate, standard error and $p$-values resulting from linear regression analysis are indicated from day 0 to 100 and day 100 to 730. Median (black dashed line) and 90th percentile (gray dotted lines) of TTV in $\mathrm{HC}$ are represented.

showed worse PFS in patients with high TTV titers at day 100 (43, 95\% CI 23-78\%) compared to patients with lower TTV titers (70, 95\%CI 57-85\%; Figure 5C), although the multivariable analysis failed to confirm this difference (Figure 5D). To gain further 

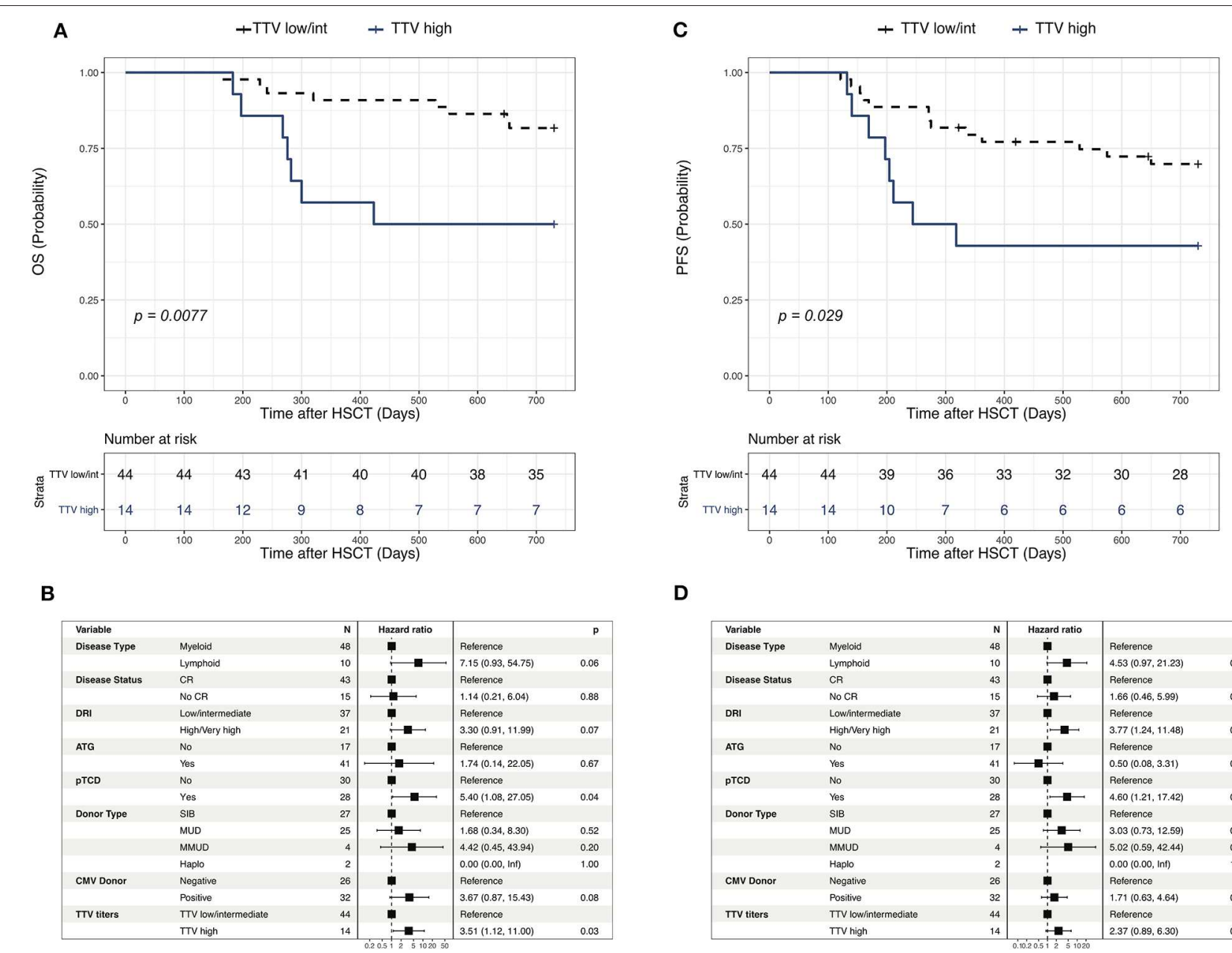

D

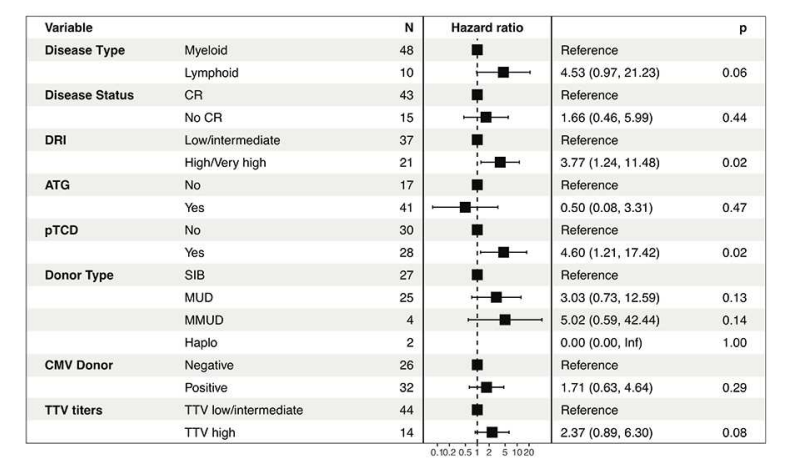

FIGURE 5 | Outcome of patients according to TTV level at d 100 post-HSCT. (A,C) Kaplan-Meier curves showing the impact of TTV level at day 100 on overall survival (OS, A) and Progression free survival (PFS, C). Comparison between high (upper quartile) and low/intermediate (first to third quartiles) TTV groups was performed using Log-rank test. (B,D) Multivariable Cox regression examining the independent impact of clinical factors on OS (B) and PFS (D). Hazard ratios (HR) along with their $95 \% \mathrm{Cl}$ are presented. High TTV levels were defined as values above the 75th percentile of the TTV titers at day 100 (>6.705 log copies/ml).

insights into reasons behind the associations between TTV titers and transplantation outcomes, we assessed the relationship between TTV titers at day 100 and occurrence of post-HSCT complications. Using the cut-off defined above, we performed cumulative incidence analysis for relapse, acute GVHD (grade 2-4) and infections (Figure 6). We observed a tendency not reaching statistical significance toward higher relapse rates in patients with higher TTV titers ( $p=0.073$; Figure 6A). Patients with high TTV titers had higher rates of acute GVHD ( $p=$ 0.026; Figure 6B), a result confirmed in a multivariable analysis $(\mathrm{HR} \pm \mathrm{SE}: 2.940 \pm 0.522, p=0.039)$ performed taking into account the abovementioned factors (disease type and status, donor type and CMV serostatus, TCD). No significant difference in 2 year cumulative incidence of infections was observed between patients groups stratified based on TTV titers. As the immune reconstitution status at day 100 is more likely to affect the infection risk at short term, we assessed the cumulative incidence of infections in the months following the measurement. Patients displaying higher TTV titers at day 100 had higher rates of infection at 6 months post-transplant ( $p$ $=0.025$; Figure $6 \mathrm{C}$ ) a result confirmed by the multivariable analysis $(2.649 \pm 0.466 ; p=0.037)$.

Collectively, these results demonstrated the association between TTV titers measured at day 100 and post-transplant complications and overall survival.

\section{DISCUSSION}

Treatment induced immune deficiency may impair the curative role of allogeneic HSCT. Clinical parameters, the type of conditioning and the patient's state before transplantation impact reconstitution of the immune system. The interaction of these numerous parameters is so complex that it becomes virtually impossible to predict the patient's immunocompetence at a given stage after HCST. Being able to assess patient's immunity is important because post-transplant interventions and therapies could be adapted accordingly. Unfortunately, no objective 
parameter reflecting the level of immune reconstitution has been established to date.

Over the past decade several groups investigated the kinetics of TTV after transplantation and asked the question whether TTV titers could serve as a comprehensive marker of posttransplant immunity. Data from solid organ transplantation where TTV titers correlate with the strength of IS (16-19) and predict infections $(18,25-27,35)$ as well as rejections $(19,21,23-$ $25,35,36)$ are encouraging. Unfortunately, the situation after HSCT seems to be more complex probably owed to the vast heterogeneity of patients and treatment modalities.

Here we report the results of a cohort of 168 patients transplanted in our center. As previously reported (31, 32, $34,37,42$ ), we found that TTV titers increased rapidly after transplantation peaking at around 100 days post-HSCT, which corresponds to the time that IS is tapered. Moreover, donor CMV positive serostatus, donor type and immune suppression resulting from GVHD requiring systemic immunosuppression influenced the restoration of anti-TTV immunity. These results are in agreement with the inverse correlation we (Figure 1C) and others (42) observed between immune reconstitution and viral titers. However, our analysis of subgroups of patients receiving in vivo and/or ex vivo $\mathrm{T}$ cell depletion failed to reveal any impact of TCD strategies on TTV titers. This apparently surprising result might be related to the lack of statistical power of the subgroup analysis and/or from the insufficient ability of total CD4 and CD8 T cell counts to reflect the functional immune status of HSCT recipients (9).

Hematopoietic cells are thought to be the main replication competent cells $(29,43-46)$. TTV titers might therefore reflect both the hematological and immunological reconstitution. Our correlation analysis between total white blood cells, a common measure of hematological reconstitution, and TTV titers failed to demonstrate any positive correlation between WBC counts and TTV titers at early time points and revealed only a negative correlation at day 100. This result suggests that, at least after hematopoietic engraftment, TTV titers are mainly influenced by the degree of immune-reconstitution.

Studies in patients after HSCT have not yet revealed whether patient or treatment related variables might impact long-term anti-TTV immunity $(30-32,34,42)$ and, more importantly, how the control of TTV replication might affect transplantation outcomes. This could be simply due to the fact that the patients in these studies were mainly monitored only during the early follow-up period when only very few patients manage to control the virus. In 2017, Wohlfarth et al. have looked beyond this early phase in a first prospective longitudinal study. We confirm their findings with respect to the impact of GVHD and/or its treatment that increase TTV titers. In addition, they found that increasing TTV titers were associated with CMV/EBV reactivation but concluded that, owed to presence of the many transplant-related confounding factors such as conditioning, GVHD and IS, they could not be predictive of other immunerelated clinical complications. More recently, in a retrospective study, Schmitz et al. (34) also investigated TTV as an early (before day 50) prognostic marker after HSCT but failed to show any association. Using multivariable analyses and cumulative
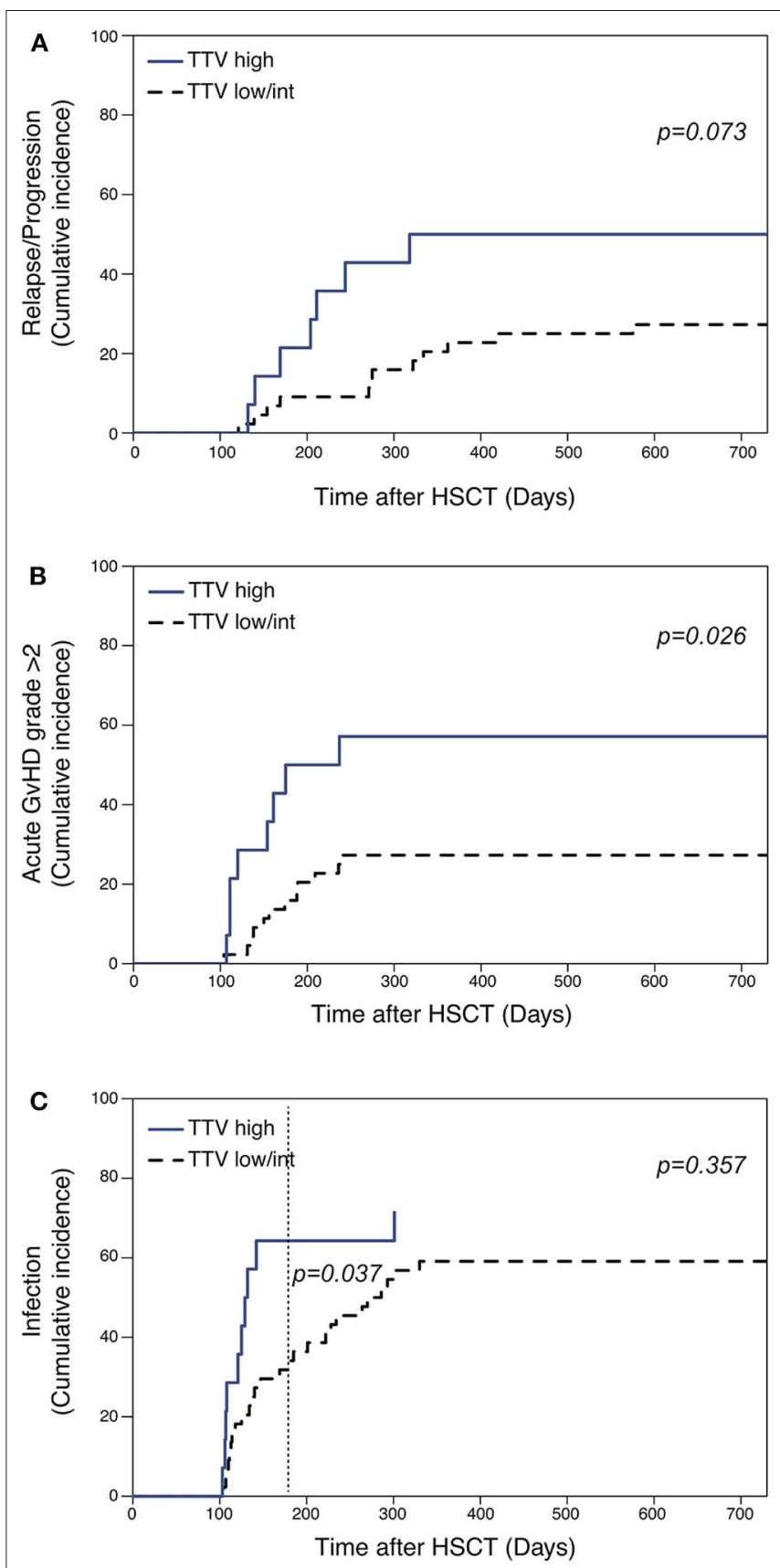

FIGURE 6 | Occurrence of post-HSCT complications according to TTV level at d 100 post-HSCT. Impact of TTV levels at day 100 on relapse (A), acute GVHD (grade $\geq 2$ ) (B) or infections (C) cumulative incidence. Competing risk factors were defined as death, GVHD requiring systemic therapy (for relapse and infections) and relapse (for GVHD and infections). High TTV levels were defined as values above the 75th percentile of the TTV titers at day 100 (>6.705 log copies $/ \mathrm{ml}$ ). Gray test was used for comparison between groups.

incidences taking into account competing events, our study overcomes some limitations encountered in previous studies and shows that high TTV titers at day 100 may be indicative of OS and flag an increased risk of GVHD and infection and possibly of relapse. Day 100 appears to be a suitable time 
point for TTV titers to be used as a prognostic biomarker. Firstly, because it is the time when TTV replication reaches its peak and starts to be affected by the degree of immune reconstitution rather than by pre-transplant factors. Secondly, because day 100 represents a time point at which critical decisions are taken regarding immunosuppressive treatment duration, antimicrobial prophylaxis and immune interventions. If confirmed, our results might pave the way to clinical trials assessing the feasibility of tailoring the prescription of immunesuppressive drugs on the TTV titers. A similar approach is currently under investigation in clinical trials in solid organ transplantation recipients (NCT04198506). Such a strategy might allow to more efficiently prevent GvHD and to limit the administration of unnecessarily high, and potentially toxic, levels of immunosuppressive treatments.

The current study, as well as most of those reported in the literature, employed an in-house assay. Future multicenter clinical trials evaluating the potential clinical use of TTV titers as a biomarker of functional immune-reconstitution after allogeneic HSCT would greatly benefit from the use of standardized methods of TTV quantification. Since the beginning of our study, a commercial kit for TTV quantification became available (TTV R-gene ${ }^{\circledR}$ kit; ARGENE ${ }^{\circledR}$, bioMérieux, France) and its use in future clinical trials could enable higher comparability between laboratories.

Our study has several limitations. First, the size of cohort we studied for our landmark analysis is small and very heterogeneous with respect to the patient's disease, state and treatment, which certainly introduces many confounders, several of which may have remained unnoticed. Because of the limited size of our cohort, our proof-of-concept analysis of the association between TTV titers at day 100 and clinical outcomes was based on an arbitrarily defined cutoff (upper quartile). Moreover, this cutoff was tested in the same cohort in whom it was established without external validation in an independent cohort. Finally, the number of patients experiencing relapse is too limited to draw any solid conclusion on the relationship between viral titers and antitumor immunity. Nevertheless, we believe that our data based on a simple laboratory test warrant further investigation in prospective multicenter clinical trials to assess TTV titers as a marker to predict complications and outcome of allogeneic HSCT.

\section{DATA AVAILABILITY STATEMENT}

The datasets generated for this study are available on request to the corresponding author.

\section{REFERENCES}

1. Kim DH, Kim JG, Sohn SK, Sung WJ, Suh JS, Lee KS, et al. Clinical impact of early absolute lymphocyte count after allogeneic stem cell transplantation. Br J Haematol. (2004) 125:217-24. doi: 10.1111/j.1365-2141.2004. 04891.x

2. Savani BN, Mielke S, Rezvani K, Montero A, Yong AS, Wish L, et al. Absolute lymphocyte count on day 30 is a surrogate for robust hematopoietic

\section{ETHICS STATEMENT}

The studies involving human participants were reviewed and approved by Commission Cantonale d'Ethique de la Recherche sur l'être humain de Genève. The patients/participants provided their written informed consent to participate in this study.

\section{AUTHOR CONTRIBUTIONS}

ER designed the study. AP and $\mathrm{CB}$ performed the experiments. AP, CD, D-LV, EB, M-CZ, and SM-L collected the clinical data. AP, ER, and FS interpreted the data and wrote the manuscript. $\mathrm{AP}$ and FS analyzed the data, performed statistical analysis, and prepared figures. LK, CT, SM-L, and YC provided overall guidance and critically revised the manuscript. All authors have approved the final version of the manuscript.

\section{FUNDING}

This work was supported by grants from the Swiss National Science Foundation (SNF 310030_144173), the Swiss Cancer Research Foundation, Geneva University Hospitals' Clinical Research Center (PRD 3-2015-I), and Dr Henri Dubois-Ferrière Dinu Lipatti Foundation.

\section{SUPPLEMENTARY MATERIAL}

The Supplementary Material for this article can be found online at: https://www.frontiersin.org/articles/10.3389/fimmu. 2020.00998/full\#supplementary-material

Supplementary Figure 1 | Correlation of TTV titers with total white blood cell (WBC) counts. Correlation of TTV titers at different time points with WBC counts. Correlations evaluated using a Spearman rank correlation coefficient test are indicated. $P<0.05$ was considered statistically significant.

Supplementary Figure 2 | Influence of relapse occurrence on TTV titer kinetics in HSCT patients. Log TTV copies/ml of plasma are represented. Patients' samples obtained after disease relapse are depicted in blue and samples obtained from patients without relapse in black. Lines represent Loess fit lines for each group and the gray area represents the $95 \% \mathrm{Cl}$ for the regression fit. Median (black dashed line) and 90th percentile (gray dotted lines) of TTV in HC are represented.

Supplementary Table 1 | Sample collection schedule and TTV titers in the study population.

Supplementary Table 2 | Correlation between TTV titers and immune reconstitution.

Supplementary Table 3 | Number of CD4 and CD8 post-HSCT according to T cell depletion.

Supplementary Table 4 | Number of CD4 and CD8 post-HSCT according to GVHD occurrence. 
4. Le Blanc $K$, Barrett AJ, Schaffer $M$, Hagglund $H$, Ljungman $P$, Ringden $\mathrm{O}$, et al. Lymphocyte recovery is a major determinant of outcome after matched unrelated myeloablative transplantation for myelogenous malignancies. Biol Blood Marrow Transplant. (2009) 15:1108-15. doi: 10.1016/j.bbmt.2009.05.015

5. Burke MJ, Vogel RI, Janardan SK, Brunstein C, Smith AR, Miller JS, et al. Early lymphocyte recovery and outcomes after umbilical cord blood transplantation (UCBT) for hematologic malignancies. Biol Blood Marrow Transplant. (2011) 17:831-40. doi: 10.1016/j.bbmt.2010.08.022

6. Thoma MD, Huneke TJ, DeCook LJ, Johnson ND, Wiegand RA, Litzow MR, et al. Peripheral blood lymphocyte and monocyte recovery and survival in acute leukemia postmyeloablative allogeneic hematopoietic stem cell transplant. Biol Blood Marrow Transplant. (2012) 18:6007. doi: 10.1016/j.bbmt.2011.08.007

7. Kim HT, Armand P, Frederick D, Andler E, Cutler C, Koreth J, et al. Absolute lymphocyte count recovery after allogeneic hematopoietic stem cell transplantation predicts clinical outcome. Biol Blood Marrow Transplant. (2015) 21:873-80. doi: 10.1016/j.bbmt.2015.01.019

8. Greco R, Ciceri F, Noviello M, Bondanza A, Vago L, Oliveira G, et al. Immune monitoring in allogeneic hematopoietic stem cell transplant recipients: a survey from the EBMT-CTIWP. Bone Marrow Transplant. (2018) 53:12015. doi: 10.1038/s41409-018-0167-8

9. Mohty B, Bel M, Vukicevic M, Nagy M, Levrat E, Meier S, et al. Graft-versus-host disease is the major determinant of humoral responses to the AS03-adjuvanted influenza A/09/H1N1 vaccine in allogeneic hematopoietic stem cell transplant recipients. Haematologica. (2011) 96:896904. doi: 10.3324/haematol.2011.040386

10. Touinssi M, Gallian P, Biagini P, Attoui H, Vialettes B, Berland Y, et al. TT virus infection: prevalence of elevated viraemia and arguments for the immune control of viral load. J Clin Virol. (2001) 21:13541. doi: 10.1016/S1386-6532(01)00157-3

11. Focosi D, Antonelli G, Pistello M, Maggi F. Torquetenovirus: the human virome from bench to bedside. Clin Microbiol Infect. (2016) 22:58993. doi: 10.1016/j.cmi.2016.04.007

12. Moen EM, Sleboda J, Grinde B. Real-time PCR methods for independent quantitation of TTV and TLMV. J Virol Methods. (2002) 104:5967. doi: 10.1016/S0166-0934(02)00039-3

13. Shibayama T, Masuda G, Ajisawa A, Takahashi M, Nishizawa T, Tsuda $\mathrm{F}$, et al. Inverse relationship between the titre of TT virus DNA and the CD4 cell count in patients infected with HIV. AIDS. (2001) 15:56370. doi: 10.1097/00002030-200103300-00004

14. Thom K, Petrik J. Progression towards AIDS leads to increased Torque teno virus and Torque teno minivirus titers in tissues of HIV infected individuals. J Med Virol. (2007) 79:1-7. doi: 10.1002/jmv.20756

15. Shang D, Lin YH, Rigopoulou I, Chen B, Alexander GJ, Allain JP. Detection of TT virus DNA in patients with liver disease and recipients of liver transplant. J Med Virol. (2000) 61:455-61. doi: 10.1002/1096-9071(200008)61:4<455::aid-jmv7>3.0.co;2-p

16. Beland K, Dore-Nguyen M, Gagne MJ, Patey N, Brassard J, Alvarez F, et al. Torque Teno virus in children who underwent orthotopic liver transplantation: new insights about a common pathogen. J Infect Dis. (2014) 209:247-54. doi: 10.1093/infdis/jit423

17. Focosi D, Macera L, Pistello M, Maggi F. Torque Teno virus viremia correlates with intensity of maintenance immunosuppression in adult orthotopic liver transplant. J Infect Dis. (2014) 210:667-8. doi: 10.1093/infdis/jiu209

18. Gorzer I, Haloschan M, Jaksch P, Klepetko W, Puchhammer-Stockl E. Plasma DNA levels of Torque teno virus and immunosuppression after lung transplantation. J Heart Lung Transplant. (2014) 33:3203. doi: 10.1016/j.healun.2013.12.007

19. Schiemann M, Puchhammer-Stockl E, Eskandary F, Kohlbeck P, RasoulRockenschaub S, Heilos A, et al. Torque Teno virus load-inverse association with antibody-mediated rejection after kidney transplantation. Transplantation. (2017) 101:360-7. doi: 10.1097/TP.0000000000001455

20. Zhong S, Yeo W, Tang M, Liu C, Lin XR, Ho WM, et al. Frequent detection of the replicative form of TT virus DNA in peripheral blood mononuclear cells and bone marrow cells in cancer patients. J Med Virol. (2002) 66:42834. doi: $10.1002 / \mathrm{jmv} .2163$
21. De Vlaminck I, Khush KK, Strehl C, Kohli B, Luikart H, Neff NF, et al. Temporal response of the human virome to immunosuppression and antiviral therapy. Cell. (2013) 155:1178-87. doi: 10.1016/j.cell.2013.10.034

22. Gorzer I, Jaksch P, Kundi M, Seitz T, Klepetko W, PuchhammerStockl E. Pre-transplant plasma Torque Teno virus load and increase dynamics after lung transplantation. PLoS ONE. (2015) 10:e0122975. doi: 10.1371/journal.pone.0122975

23. Gorzer I, Jaksch P, Strassl R, Klepetko W, Puchhammer-Stockl E. Association between plasma Torque teno virus level and chronic lung allograft dysfunction after lung transplantation. J Heart Lung Transplant. (2017) 36:366-8. doi: 10.1016/j.healun.2016.10.011

24. Simonetta F, Pradier A, Masouridi-Levrat S, van Delden C, Giostra E, Morard I, et al. Torque Teno virus load and acute rejection after orthotopic liver transplantation. Transplantation. (2017) 101:e21921. doi: 10.1097/TP.0000000000001723

25. Jaksch P, Kundi M, Gorzer I, Murakozy G, Lambers C, Benazzo A, et al. Torque Teno virus as a novel biomarker targeting the efficacy of immunosuppression after lung transplantation. J Infect Dis. (2018) 218:19228. doi: 10.1093/infdis/jiy452

26. Maggi F, Focosi D, Statzu M, Bianco G, Costa C, Macera L, et al. Early post-transplant torquetenovirus viremia predicts cytomegalovirus reactivations in solid organ transplant recipients. Sci Rep. (2018) 8:15490. doi: 10.1038/s41598-018-33909-7

27. Strassl R, Schiemann M, Doberer K, Gorzer I, Puchhammer-Stockl E, Eskandary F, et al. Quantification of Torque Teno virus viremia as a prospective biomarker for infectious disease in kidney allograft recipients. $J$ Infect Dis. (2018) 218:1191-9. doi: 10.1093/infdis/jiy306

28. Focosi D, Maggi F, Albani M, Macera L, Ricci V, Gragnani S, et al. Torquetenovirus viremia kinetics after autologous stem cell transplantation are predictable and may serve as a surrogate marker of functional immune reconstitution. J Clin Virol. (2010) 47:189-92. doi: 10.1016/j.jcv.2009.11.027

29. Maggi F, Focosi D, Albani M, Lanini L, Vatteroni ML, Petrini M, et al. Role of hematopoietic cells in the maintenance of chronic human torquetenovirus plasma viremia. J Virol. (2010) 84:6891-3. doi: 10.1128/JVI.00273-10

30. Masouridi-Levrat S, Pradier A, Simonetta F, Kaiser L, Chalandon Y, Roosnek E. Torque teno virus in patients undergoing allogeneic hematopoietic stem cell transplantation for hematological malignancies. Bone Marrow Transplant. (2016) 51:440-2. doi: 10.1038/bmt.2015.262

31. Albert E, Solano C, Pascual T, Torres I, Macera L, Focosi D, et al. Dynamics of Torque Teno virus plasma DNAemia in allogeneic stem cell transplant recipients. J Clin Virol. (2017) 94:22-8. doi: 10.1016/j.jcv.2017.07.001

32. Gilles R, Herling M, Holtick U, Heger E, Awerkiew S, Fish I, et al. Dynamics of Torque Teno virus viremia could predict risk of complications after allogeneic hematopoietic stem cell transplantation. Med Microbiol Immunol. (2017) 206:355-62. doi: 10.1007/s00430-017-0511-4

33. Albert E, Solano C, Gimenez E, Focosi D, Perez A, Macera L, et al. The kinetics of torque teno virus plasma DNA load shortly after engraftment predicts the risk of high-level CMV DNAemia in allogeneic hematopoietic stem cell transplant recipients. Bone Marrow Transplant. (2018) 53:1807. doi: 10.1038/bmt.2017.235

34. Schmitz J, Kobbe G, Kondakci M, Schuler E, Magorsch M, Adams O. The value of Torque Teno Virus (TTV) as a marker for the degree of immunosuppression in adult patients after hematopoietic stem cell transplantation (HSCT). Biol Blood Marrow Transplant. (2019) 26:64350. doi: 10.1016/j.bbmt.2019.11.002

35. Frye BC, Bierbaum S, Falcone V, Kohler TC, Gasplmayr M, Hettich I, et al. Kinetics of Torque Teno virus-DNA plasma load predict rejection in lung transplant recipients. Transplantation. (2019) 103:81522. doi: 10.1097/TP.0000000000002436

36. Strassl R, Doberer K, Rasoul-Rockenschaub S, Herkner H, Gorzer I, Klager JP, et al. Torque Teno virus for risk stratification of acute biopsy-proven alloreactivity in kidney transplant recipients. J Infect Dis. (2019) 219:19349. doi: 10.1093/infdis/jiz039

37. Albert E, Solano C, Gimenez E, Focosi D, Perez A, Macera L, et al. Kinetics of Alphatorquevirus plasma DNAemia at late times after allogeneic hematopoietic stem cell transplantation. Med Microbiol Immunol. (2019) 208:253-8. doi: 10.1007/s00430-019-00586-w 
38. Chalandon Y, Roosnek E, Mermillod B, Waelchli L, Helg C, Chapuis B. Can only partial T-cell depletion of the graft before hematopoietic stem cell transplantation mitigate graft-versus-host disease while preserving a graft-versus-leukemia reaction? A prospective phase II study. Biol Blood Marrow Transplant. (2006) 12:102-10. doi: 10.1016/j.bbmt.2005. 09.010

39. Tyagi AK, Pradier A, Baumer O, Uppugunduri CR, Huezo-Diaz P, PosfayBarbe KM, et al. Validation of SYBR green based quantification assay for the detection of human Torque Teno virus titers from plasma. Virol J. (2013) 10:191. doi: 10.1186/1743-422X-10-191

40. Tapparel C, Cordey S, Van Belle S, Turin L, Lee WM, Regamey N, et al. New molecular detection tools adapted to emerging rhinoviruses and enteroviruses. J Clin Microbiol. (2009) 47:1742-9. doi: 10.1128/JCM.02339-08

41. Roux E, Dumont-Girard F, Starobinski M, Siegrist CA, Helg C, Chapuis $\mathrm{B}$, et al. Recovery of immune reactivity after T-cell-depleted bone marrow transplantation depends on thymic activity. Blood. (2000) 96:2299303. doi: 10.1182/blood.V96.6.2299

42. Wohlfarth P, Leiner M, Schoergenhofer C, Hopfinger G, Goerzer I, Puchhammer-Stoeckl E, et al. Torquetenovirus dynamics and immune marker properties in patients following allogeneic hematopoietic stem cell transplantation: a prospective longitudinal study. Biol Blood Marrow Transplant. (2018) 24:194-9. doi: 10.1016/j.bbmt.2017.09.020

43. Maggi F, Fornai C, Zaccaro L, Morrica A, Vatteroni ML, Isola P, et al. TT virus (TTV) loads associated with different peripheral blood cell types and evidence for TTV replication in activated mononuclear cells. J Med Virol. (2001) 64:190-4. doi: 10.1002/jmv.1035
44. Mariscal LF, Lopez-Alcorocho JM, Rodriguez-Inigo E, Ortiz-Movilla N, de Lucas S, Bartolome J, et al. TT virus replicates in stimulated but not in nonstimulated peripheral blood mononuclear cells. Virology. (2002) 301:1219. doi: 10.1006/viro.2002.1545

45. Focosi D, Macera L, Boggi U, Nelli LC, Maggi F. Short-term kinetics of torque teno virus viraemia after induction immunosuppression confirm $\mathrm{T}$ lymphocytes as the main replication-competent cells. J Gen Virol. (2015) 96(Pt. 1):115-7. doi: 10.1099/vir.0. 070094-0

46. Kosulin K, Kernbichler S, Pichler H, Lawitschka A, Geyeregger R, Witt V, et al. Post-transplant Replication of Torque Teno Virus in Granulocytes. Front Microbiol. (2018) 9:2956. doi: 10.3389/fmicb.2018. 02956

Conflict of Interest: The authors declare that the research was conducted in the absence of any commercial or financial relationships that could be construed as a potential conflict of interest.

Copyright (C) 2020 Pradier, Masouridi-Levrat, Bosshard, Dantin, Vu, Zanella, Boely, Tapparel, Kaiser, Chalandon, Simonetta and Roosnek. This is an open-access article distributed under the terms of the Creative Commons Attribution License (CC BY). The use, distribution or reproduction in other forums is permitted, provided the original author(s) and the copyright owner(s) are credited and that the original publication in this journal is cited, in accordance with accepted academic practice. No use, distribution or reproduction is permitted which does not comply with these terms. 